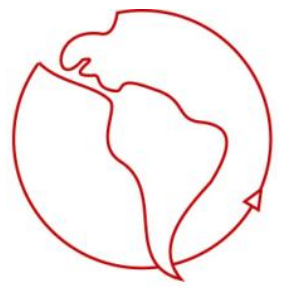

\title{
La Trasgresión Identitaria y Comunicativa de la Posmodernidad
}

Maximiliano Soto Sepúlveda

Magíster en Antropología y Desarrollo, Universidad de Chile

maxiclio@ hotmail.com

'Nous ne vivons ensemble qu' en perdant notre identité; inversement, le retour des communautés entraine avec lui l' appel à l' homogénéité, à la pureté, à l' unité, et la communications est remplacée par la guerre entre ceux qui offrent des sacrifices à des dieux différents, en appellement à des traditions étrangères ou opposées les unes aux autres ..."

Alain Touraine

"La intolerancia por lo diferente o por lo desconocido es natural en el niño, tanto como el instinto de apoderarse de todo lo que desea. Al niño se lo educa a la tolerancia poco a poco, así como se lo educa al respeto por la propiedad ajena y, antes aún, al control del propio esfínter. Desafortunadamente, si todos llegan al control del propio cuerpo, la tolerancia sigue siendo un problema de educación permanente de los adultos, porque, en la vida cotidiana, estamos expuestos siempre al trauma de la diferencia."

Umberto Eco

\section{Introducción}

En un mundo donde prima la individualidad sin un proceso de subjetividad atingente en la aceptación de la otredad y en el fortalecimiento de las identidades dentro de un contexto de posmodernidad, surge la necesidad apremiante de resaltar realidades de integración acentuada en las identidades y pertenencias entre diversos universos simbólicos, mediante lo cual se logre insertar estrategias de asimilación entre las múltiples alteridades o mecanismos que ayuden en el reconocimiento del uno por el otro.

Desde lo conceptual la modernidad abarca diversos ámbitos que van desde lo económico, a lo cultural, pasando por lo político. Actualmente en lo que respecta a lo económico, se ve que en América Latina, y en el mundo en general, se presenta una "mundialización de la economía, que produce una universalización de criterios y racionalización de mercados" (CEPAL 1997:7) acompañada de un debilitamiento del Estado, en pro de una integración mas allá de los límites nacionales y continentales, junto a una revolución tecnológica. Hay un claro acento en el continuo progreso de diversas técnicas y saberes científicos: "El continuo e imparable progreso de las ciencias y de las técnicas hace que se den grandes cambios en el campo de la producción (división del trabajo, con las consiguientes transformaciones en las costumbres y en la cultura tradicional)[...] A estos aspectos señalados se han de añadir la explosión demográfica, la concentración urbana y el gigantesco desarrollo de los medios de comunicación y de información, cuestiones todas ellas que dejarán su huella de un modo decisivo en la modernidad como práctica social basada en el cambio, la innovación, la inestabilidad y en la permanente crisis" (Vattimo 1990:46).

Estos son los efectos que desde el siglo XVIII se han ido configurando hasta asumir una posición primordial dentro de la red social, y que han ido construyendo el mundo presente liderado por progresos científicos y vanguardias artísticas, lo que para algunos filósofos han ido estableciendo paulatinamente la globalización del mundo, que habría puesto fin a las diferencias del sujeto, cayendo en un uniformalismo de las diversas tendencias, "la diversidad culturales ahora mucho mayor que hace quince o treinta años [...] la posmodernidad se caracterizaría, pues, por esta aceptación desprejuiciada de lo plural y por una tendencia a desjerarquizar las diferentes tendencias o personalidades. La actitud posmoderna es, por lo 
tanto, menos unitaria que la moderna" (Ramírez 1990:61). Es en este plano que las identidades se han fragmentado haciendo resaltar una necesaria evaluación y rediscusión acerca de la posmodernidad, en pro de un análisis exhaustivo de lo positivo y negativo del crecimiento social y humano en los últimos siglos.

Es desde esta perspectiva que intentaremos construir una argumentación acerca de la posmodernidad, de una apremiante integración en favor de las identidades, y de la importancia de la comunicación en los sujetos, como pilar inicial en la fundación de un sistema político, económico y cultural centrado en la participación social, teniendo presente el principal efecto de estas últimas décadas: "La revolución tecnológica ha contribuido a lo que se ha dado llamar la desterritorialización de la cultura y de las identidades" (CEPAL 1997:7). Para hilar esta argumentación y crítica nos centraremos en los paradigmas sociales de Samuel Arriaran, Jürgen Habermas y Alain Touraine, desde donde iremos fundamentando los pertinentes conceptos y problemáticas sociales para dar curso a un llamado hacia la sociedad civil y a la necesidad de asumir un rol de neoparticipantes después de intentar analizar el caso del municipio santiaguino de La Florida, como un ejemplo de identidad fragmentada.

\section{Paradigmas en la Posmodernidad: Arriarán, Habermas y Touraine}

\section{Modernidad: Modernización y Modernismo}

Para aproximarnos a nuestra problematización citamos la conceptualización que nos da Samuel Arriarán: "La modernidad se entiende como una etapa histórica. La modernización como un proceso socioeconómico que trata de ir construyendo la modernidad, y el modernismo como el proyecto cultural que trata de seguir a la modernidad[...]La modernidad como experiencia histórica significa principalmente desarrollo, que a su vez implica dos cosas: a) Las transformaciones ocasionadas por el mercado mundial a nivel de lo económico (modernización). b) Las transformaciones a nivel de lo subjetivo. Lo que tiene que ver con el autodesarrollo individual (modernismo)" (Arriarán 1997:155-156). De esta manera queda claro que hay un aspecto de carácter económico ligado a la técnica, y a la ciencia, y a las relaciones comerciales dentro de un mercado regional y mundial cada vez más amplio; y por otro lado un aspecto de carácter cultural ligado a las costumbres y expresiones artísticas que tratan de dar cierto contexto a esta experiencia de progreso histórico con sus efectos, defectos y afectos hacia las diversas comunidades, y hacia los diversos sujetos que pueblan el mundo. Esto no quiere decir que ambos elementos señalados vayan juntos de la mano, ya que perfectamente podemos hablar de un crecimiento económico ligado al concepto de modernización, por un lado, al momento de sofisticar el emplazamiento de una planta hidroeléctrica, y por otro, no respetar el aspecto cultural que rodea dicha emplazamiento, relacionada a las comunidades que viven entorno al lugar, pasado a llevar patrones culturales, como son los cementerios indígenas y lugares sagrados de asentamiento que han caracterizado algunas regiones por cientos de años.

Por lo tanto la modernización en su esencia de progreso y de crecimiento puede ir perfectamente en desmedro del modernismo como constituyente cultural, un choque que puede verificarse al indagar la situación actual que presentan las comunidades indígenas a lo largo de Latinoamérica, por poner un ejemplo, comunidades que por lo general no son consideradas en un plano de integración económica reconociendo su identidad cultural.

Situación que se reafirmar al observar las ventajas que han desarrollado dichas comunidades gracias a la mundialización de las comunicaciones, constatando que "hay una tendencia actual hacia el internacionalismo cultural. Sin embargo, lo que parece desarrollarse después del derrumbe del "socialismo real" es justamente un resurgimiento de las tradiciones y valores de las culturas indígenas" (Arriarán 
1997:163).Algo que se puede notar concretamente en el caso de Chiapas, en México, o de los mapuches, en Chile, desde una postura revisionista.

Es dentro de este contexto de posmodernidad como proyecto inacabado de la modernidad, donde encontramos estas situaciones de reflejo, de espejo donde constatamos el encuentro de identidades, de realidades sociales y de universos simbólicos equidistantes dentro de mecanismos de inclusión necesarios y de exclusión comunes.

\section{Pragmática del Lenguaje: Construyendo Identidades}

El tema de la integración dentro de la experiencia posmoderna, comienza por un entendimiento y fortalecimiento de la identidad del sujeto como unidad indivisible, e individual en su posición de ente social; paro lo cual es necesario precisar el concepto de identidad, y luego su configuración y sus componentes.

La identidad "se refiere a los términos por medio de los cuales un individuo se describe a sí mismo; se relaciona a la autoimagen y la imagen que los demás tienen de uno. La identidad nos confronta con el tema de lo propio y lo ajeno, con lo interior y exterior, con el tema del otro. Para la constitución del yo, para el establecimiento de relaciones objetuales, para la constitución del sí mismo o para la imagen especular, el otro es central. En tanto, la identidad étnica, es decir, la identidad que comparte un grupo o población históricamente constituido, implica un sentido personal de lealtad hacia el grupo que constituye una cultura. Esta forma de identidad social se basa en un sentimiento de pertenencia y reconocimiento, en donde la diferencia con otros grupos (o culturas) se torna importante" (CEPAL 1997:13). En esta definición notamos dos aspectos a destacar, por un lado la diferenciación que se hace del Uno con respecto al Otro, y como se lleva al plano de la propiedad conceptualizada en la diferenciación de lo propio con respecto a lo ajeno, pero el uno es más que propiedad material, es propiedad en sí mismo, se autopertenece ontológicamente; y por otro lado el elemento de pertenencia al grupo por un aspecto de compromiso o de lealtad, lo que explicaría la identidad que se forja al interior de una comunidad indígena o de una tribu urbana.

Respecto al concepto de identidad el filósofo Jürgen Habermas, considera ciertos aspectos que explicitan éste concepto: "Según el modelo kantiano, los sujetos son libres en la medida en que tienen conciencia de sí mismos, en la medida en que guardan una relación de identidad para consigo mismos; mas en una tal identidad vuelven a perder su libertad desde el momento en que están sujetos a la coerción que de ella dimana y que ellos mismos perpetúan. Carentes de libertad son los sujetos en cuanto naturaleza no idéntica, difusa y, sin embargo, libres, pues en los impulsos que de ellos se adueñan, se liberan a su vez del carácter forzoso de la identidad [...] La identidad del yo designa la competencia de un sujeto capaz de lenguaje y acción para dar satisfacción a determinadas exigencias de consistencia [...] La identidad se genera a través de la socialización, esto es : por el hecho de que el adolescente sólo acierta a integrarse en un sistema social determinado por la vía de la apropiación de generalidades simbólicas, mientras que, ulteriormente, se refuerza y despliega por la individuación, o lo que es igual, por la vía precisamente de una creciente independencia con respecto a los sistemas sociales" (Habermas 1986:62-63). Habermas contribuye señalando dos aspectos importantes en la conformación de la identidad como entidad ontológica al ser, por un lado la libertad del sí mismo, sin la cual no habría identidad en relación a una capacidad de decidir por sí mismo, y el lenguaje como mecanismo de construcción, ya que a través de el nos comunicamos con uno mismo, y damos fortaleza al sí mismo, y sólo a través del lenguaje entramos en contacto con el alter, con el otro como entidad también única, mediante lo cual se configura también una suerte de pertenencia. Habermas plantea que la identidad se genera como un acto de socialización por la vía de una apropiación de "generalidades simbólicas", lo que se aclara al diferenciar la identidad centrada 
en los roles que se cumplen, y la identidad del yo: "En la medida de que el niño hace suyas las generalidades simbólicas de un reducido conjunto de roles fundamentales de su entorno familiar y, más tarde, las normas de acción de grupos más amplios (el colegio), a su identidad natural se sobrepone una identidad de roles de base simbólica. Propiedades corporales tales como el sexo, la dotación física, la edad, etc., quedan asumidas para las definiciones simbólicas. En este plano, los actores aparecen primero como personas de referencia dependientes de roles y más tarde también como anónimos titulares de roles [...] La identidad de roles se ve sustituida por la identidad del yo; los actores, a través, por así decirlo, de sus contextos vitales objetivos, se encuentran ahora a título de individuos" (Habermas 1986:75). De esta manera deja claro la configuración de la identidad como acto de socialización, en que luego de una etapa de cumplimiento a otros mismos se consolida el sí mismo en la perspectiva social de los individuos; pero no hay que olvidar que el lenguaje juega un papel crucial en esta consolidación. "La lograda identidad del yo significa la peculiar capacidad de los sujetos dotados de lenguaje y aptos para la acción de permanecer idénticos a sí mismos aún también en el caso de transformaciones profundas de un sistema de personalidad por medio de las que reacciona a situaciones contradictorias. Los atributos de la autoidentificación, por lo demás, deben estar reconocidos intersubjetivamente, si es que pretenden fundamentar la identidad de una persona. El diferenciarse de otros ha de estar reconocido por esos otros. La unidad simbólica de la persona, se basa por su parte en la pertenencia a la realidad simbólica de un grupo, en la posibilidad de localizar en el mundo a ese grupo" (Habermas 1986:86-87).

A partir de este fundamento podemos desprender que el ser uno en sí mismo, con la constitución de una identidad, no tendría ninguna consistencia sin el reconocimiento por parte de la comunidad, o del otro, y sin el identificarse perteneciendo a un grupo; habría una íntima conexión entre la identidad y la identificación como tal, a partir de lo cual el sujeto se conectaría con lo social. Para Habermas el ámbito social en que se han forjado los sujetos es importantísimo, ya que delata las identidades en esencia, dentro de la cual el lenguaje, y en específico la comunicación como actos del habla es crucial: “...los participantes en la interacción no pueden aparecer ya como autores que con la ayuda de acciones imputables dominan situaciones, sino como producto de las tradiciones en que están, de los grupos solidarios a que pertenecen y de los procesos de socialización en que han crecido. Pues el mundo de la vida se reproduce en la medida en que se cumplen estas tres funciones que rebasan esta perspectiva del actor, [...]: la prosecución de tradiciones culturales, la integración de grupos a través de normas y valores y la socialización de cada generación siguiente. Lo que así obtenemos son propiedades de los mundos de la vida comunicativamente estructurados, en general" (Habermas 1989:356). Es decir las tradiciones, la integración y la socialización serían los tres componentes que permitirían según este filósofo la conformación de un grupo social que se autoidentifique a sí mismo en relación a sus integrantes, y que a la vez se articule hacia el futuro, teniendo un pasado sólido como referente.

Es necesario señalar que Habermas tiene una visión optimista de la modernidad, a diferencia de sus otros pares de la escuela de Frankfurt, como Adorno, Horkheimer y Marcusse, que centraban sus argumentos en la teoría crítica a la modernidad como un proyecto acabado de individualización, y atomización de la sociedad, pero Habermas plantea que la modernidad, como experiencia histórica, no ha terminado, y es necesario revalorarla en sus aspectos positivos, para lo cual plantea una reconstrucción del materialismo histórico a partir del lenguaje, desde lo cual configura su teoría de la acción comunicativa.

La teoría de la acción comunicativa trataremos de conducirla a través de nuestro argumento central en favor de la integración del reconocimiento de las identidades diversas como urgencia necesaria en un contexto de posmodernidad. Esta teoría le da un argumento más sólido a su postura acerca de las identidades, y de la legitimación de éstas; su punto de partida es la razón comunicativa desde donde define racionalidad como "toda la disposición de los sujetos capaces de lenguaje y acción para adquirir y utilizar conocimiento falible [...] la racionalidad tiene su medida en cómo se orienta el sujeto solitario por los 
contenidos de sus representaciones y enunciados [...] la racionalidad encuentra su medida en la facultad que participantes en la interacción capaces de dar razón de sus actos tienen de orientarse por pretensiones de validez enderezadas a ser intersubjetivamente reconocidas" (Habermas 1989:373). De esta manera define una racionalidad en pro del lenguaje, a partir de la cual se generaría una acción comunicativa centrada en actos comunicativos, reflejando toda la influencia del círculo de Viena a través de Witsgenstein, de la escuela lógica inglesa a través de Austin, y de John Searle y su teoría sobre los actos del habla.

Habermas a través de su teoría de la acción comunicativa une sus argumentos anteriores acerca de la importancia de las tradiciones y de la socialización en la configuración de las identidades, señalando: "La razón que se expresa en la acción comunicativa establece una mediación con las tradiciones, las prácticas sociales y los complejos de experiencia ligados al cuerpo, todo lo cual se funda en cada caso en una totalidad particular" (Habermas 1989:386). En su teoría se explicitan los actos del habla para determinar cuales son los mecanismos que permiten desde la acción configurar conocimiento, estableciendo que sólo la solidez de las argumentaciones y de los enunciados van configurando criterios de validez frente a un conocimiento que es en esencia falible, ya que sin argumentos sólidos es fácil de destruir. En este enfoque el lenguaje y la comunicación se perfilan como los ingredientes esenciales de la acción o de la pragmática: "El modelo normativo de la acción concibe el lenguaje como un medio que transmite valores culturales y que es portador de un consenso que simplemente queda ratificado con cada nuevo acto de entendimiento [...] el entendimiento linguiístico es sólo el mecanismo de coordinación de la acción, que ajusta los planes de acción y las actividades teleológicas de los participantes para que puedan constituir una interacción" (Habermas 1987:137); es a través de este entendimiento, de este consenso, que de la identidad del uno se transcurre a la identificación con el otro, mediante los actos del habla: "El concepto de acción comunicativa presupone el lenguaje como un medio dentro del cual tiene lugar un tipo de proceso de entendimiento en cuyo transcurso los participantes, al relacionarse con un mundo, se presentan unos frente a otros con pretensiones de validez que pueden ser reconocidas o puestas en cuestión" (Habermas 1987:143).

En relación a los actos del habla establece tres tipos. Primero están las locuciones como actos primarios de comunicación sin una segunda intención, en segundo lugar plantea las ilocuciones como actos secundarios en que se plantea una intención con un plus, como el decir me gusta tu rosa pero prefiero la mía; y en tercer lugar plantea las perlocuciones, en donde hay una clara segunda intención, centrada en el querer lograr un efecto en el receptor del mensaje, que se ejemplifica al decir mi rosa es más bella porque es abonada con un fertilizante especializado; las perlocuciones corresponden al lenguaje utilizado por la publicidad, y para que logren el efecto esperado tienen que hacerse pasar necesariamente por ilocuciones. Habermas proyecta esta tipificación de los actos del habla a la legitimación de los ordenes políticos, o como él las llama a las sociedades del capitalismo tardío, oponiéndose a la teoría sistémica de Luhmann, y criticando las tecnocracias elitarias que centran su poder en el uso de perlocuciones para vender un discurso político en específico centrado en el conocimiento científico de ciertos grupos de poder, algo que se hace presente en la historia de Latino América con gobiernos tecnocráticos como fue el caso del PRI en México , y la adopción política de sistemas económicos neoliberalistas de mercado. "La legitimidad significa que la pretensión que acompaña a un orden político de ser reconocido como correcto y justo no está desprovista de buenos argumentos, un orden legitimo merece reconocimiento [...], las sociedades del capitalismo tardío no presentan tendencias espontáneas de autorregulación, sino, más bien, tendencias al desequilibrio. Estas se muestran en la relación entre el desarrollo de los subsistema: económico, político y técnico en relación al mundo de la vida y en la tendencia a la pérdida de legitimidad y al aumento de las patologías sociales" (Cuadernos Cendes 1990:279-280). 
El problema de los sistemas políticos es que no han sido avalados por un amplio reconocimiento, por lo cual no han sido legitimados en base a una ratificación, en tanto no se han respetado las identidades en pro de una integración; y ha esto se refiere Habermas con patologías sociales, algo que se vincula estrechamente con el problema indígena, que se ha ido desplazando sucesivamente, frente a lo cual la única solución es ampliar la base de la discusión política en relación a lo que Habermas señala como Democracia participativa, centrada en los principios de autorrealización, autonomía y autodeterminación, a través de la comunicación como acción comunicativa: “... la democracia es una forma de vida, no sólo un método político, como sostiene en las teorías elitarias, en el cual se hacen valer intereses generalizables [...] En una situación democrática todos los intereses legítimos pueden ser satisfechos mediante la realización del interés fundamental de la autodeterminación y la participación [...] la libertad política se concibe como la libertad de un sujeto que se autodetermina y se autorrealiza. Autonomía y autorrealización son los conceptos claves de una praxis que lleva inherente su propia finalidad: la producción y reproducción de una vida digna" (Cuadernos Cendes 1990:281).

De esta manera a partir del concepto de identidad, se configura una teorización desde la cual finalmente se propone un sistema político que vele por proteger la identidad del uno y del otro en pro de lograr la integración, y no la exclusión de carácter cultural. Es en ese sentido que en Latino América se ha primado una modernización en desmedro de un modernismo, por alcanzar altos niveles de crecimiento económico se han atentado contra las diferencias culturales, que por no reconocerlas y no entenderlas se les ha excluido de un proyecto vital, y no se les ha permitido aportar con su riqueza cultural, estableciendo una negación de lo ajeno frente a lo propio. En este contexto las comunidades indígenas han fortificado su discurso étnico en los últimos años, lo que permite para algunos autores diferenciar entre modernismo y posmodernismo: "La diferencia fundamental entre el posmodernismo y el modernismo es que mientras el modernismo supone una orientación hacia el futuro, el posmodernismo lo hace hacia el pasado. En este sentido, el posmodernismo tiende a rescatar los estilos y valores de la antigüedad, sin marcar suficientemente los elementos de discontinuidad, lo que permitiría explicar la situación de que hoy las culturas indígenas parecen disgregarse a raíz de la globalización económica y cultural. Pero también, parecen estar redefiniendo el patrimonio cultural para ajustarse a condiciones históricas distintas. Esto implica que las identidades culturales preexistentes son inadecuadas e insuficientes para expresar las nuevas necesidades sociales" (Arriarán 1997:218-219). Esto explicaría la situación en Chiapas, y en lo eventual, la radicalización del discurso mapuche frente a las autoridades de gobierno en Chile, lo que no implica dejar de lado sus identidades y patrones culturales de antaño, sino que adecuarse en el discurso, en las ilocuciones necesarias para defender sus argumentos, y llegar a entendimientos de consenso en defensa y reconocimiento de su identidad, frente a la alteridad de gobierno. Es de esta manera que la globalización y la modernidad en Latino América si bien se caracteriza por constituir polos desintegradores de las múltiples diferencias, esta revitalizando, y reafirmando la discusión étnica en un contexto de injusticias sociales, desigualdades, y de un constante dominio de una cultura por sobre otras, en donde las identidades diversas deben integrarse en pro de un sano progreso histórico.

\section{Identificación y Participación Política en la Posmodernidad}

El concepto de democracia participativa en Habermas se relaciona en algunos aspectos con los planteamientos de Alain Touraine, acerca de la Democracia, y de la revaloración del sujeto como ente único. Touraine también crítica en cierta medida las concepciones elitistas acerca de la conformación del poder político al señalar que: "La democracia es imposible si un actor se identifica con la racionalidad universal y reduce a los otros a la defensa de su identidad particular. Es por eso que la modernización occidental se hizo a menudo de manera antidemocrática" (Touraine 1995:201), lo que critica las tecnocracias sustentadas en la venta de un discurso político a la comunidad, sin la ratificación, y sin el reconocimiento necesario. Por democracia define: “...espacio institucional que protege los esfuerzos del 
individuo o del grupo para formarse y hacerse reconocer como sujetos" (Touraine 1995:184). Deja claro que no hay democracia sin conciencia de pertenencia a una colectividad política, en donde diferencia sujeto de individuo, el individuo sería el uno, el sí mismo con su identidad autónoma, y el sujeto sería la proyección del individuo en el campo de lo societal. Por lo tanto también nos habla al igual que Habermas de un sujeto en sí mismo: "El sujeto integra identidad y técnicas, construyéndose como actor capaz de modificar su medio ambiente y de hacer de sus experiencias de vida pruebas de su libertad [...] El sujeto es un principio moral en ruptura con la moral del deber que asocia la virtud con el cumplimiento de un rol social. El individuo se convierte en sujeto, no cuando se identifica con la voluntad general... sino al contrario cuando se libera de las normas sociales del deber del Estado...” (Touraine 1995:182).

El individuo se convertiría en sujeto no cuando acata el sometimiento de normas a las cuales tiene que entregar su identidad, sino que cuando su identidad como sí mismo es reconocida e incorporada por el Estado, por el sistema político; en ese sentido para Touraine la democracia no sólo es un sistema político, sino que también una forma de vida que debiera incorporar la proyección de los diversos individuos en sujetos: "La idea democrática impone reconocer el pluralismo cultural aún mas que el pluralismo social, la democracia debe ayudar a los individuos a ser sujetos, a obtener en ellos, tanto en sus prácticas como en sus representaciones, la integración de su racionalidad, es decir de su capacidad de manejar técnicas y lenguajes, y de su identidad, que descansa sobre una cultura y una tradición a las que reinterpretan constantemente en función de las transformaciones del método técnico [...] El sujeto no como un nuevo sol, que ilumine la vida social, sino como una red de comunicaciones entre los dos universos de la objetividad y de la subjetividad" (Touraine 1995:187-188).

Uno de los principios fundamentales para coordinar la modernización de un campo específico de la sociedad, sea política, salud, justicia, o educación, es generar códigos de coordinación entre el sistema específico y el sistema social contextual. "Los programas deben ser sometidos a una puesta en cuestión periódica tratando de introducir en ellos los conocimientos exigidos por los progresos de la ciencia y los cambios de la sociedad" (Bourdieu 1998:131). No puede generarse una ruptura social, mediante la implantación de un proyecto foráneo de modernización política antidemocrática sin que este vinculado y asociado a los habitus de reproducción cultural del lugar; es fundamental que las modernizaciones vayan a la par con formas prácticas y teóricas, donde los adquirientes de conocimiento apliquen la información en diversos contextos, uniendo y equilibrando el trabajo cuantitativo con el cualitativo, ya que los proyectos que se aplican en forma descontextualizada fragmentan y excluyen identidades diversas.

\section{El Municipio de La Florida. Un caso de Identidad Fragmentada}

Nos interesa analizar el quehacer del espacio social en cuanto espacio de articulación del quehacer cotidiano, para lo cual ocupamos el concepto de las representaciones sociales en el sentido de que son "maneras de pensar y de interpretar nuestra realidad cotidiana, lo que nos permite llegar a un conocimiento socialmente elaborado y compartido, mediante actos que terminan por sernos habituales" (Jodelet 1986:473); y que están definidas por un contenido (informaciones o actitudes) respecto a un objeto (situaciones o instituciones), a través de las cuales los sujetos explican su mundo conocido mediante sistemas de referencias que le dan coherencia al mundo, a través de las cuales justifican lo que comprenden y lo que no comprenden. Esta referencia es válida para el grupo que la construye, en cuyo proceso interviene lo individual y lo colectivo, las experiencias compartidas, el contexto y las características culturales del individuo y del grupo al cual pertenece; configurando un sistema de significado desde el cual legitiman, mediante códigos, lo que es mutuamente compartido.

Esta referencia conceptual nos permitirá visualizar, de manera crítica, ciertas problemáticas que rodean a los sujetos dentro de un campo social posmoderno, como es el caso de un individualismo asistido que 
perjudicaría al no lograr generar participación en la política o en otros campos sociales. Es desde esta perspectiva que consideramos la municipalidad de La Florida como variable en la construcción de representaciones sociales no participativas, en el sentido de que sería un espacio que influiría en la apatía que tienen los jóvenes de participar en el territorio al cual pertenecen; para lo cual es necesario citar algunos antecedentes referentes a las políticas públicas comunales: "Desde 1980, con la consolidación del modelo económico y político neoliberal se ha implementado una estrategia global de descentralización administrativa del Estado, en la cual el municipio ha alcanzado un rol y un status diferente al que ha tenido en su tradición histórica. La nueva política ha desarticulado el populismo tradicional tanto la característica cultural de masas; pero, a la vez, no ha logrado sustituirlo por una cultura propiamente municipalista o ciudadana" (Benítez 1998:62). Esta nueva estrategia consistió en dotar de autonomía al espacio municipal, para acrecentar la participación y la articulación política ciudadana desde lo localcomunal, pero hay que tener presente que esta lógica de desregulación y de creciente individualismo, producto del contexto y del sistema económico neoliberal, quiebra con las identificaciones comunitarias, pese a los intentos de reestructurar la municipalidad a comienzo de la década de lo 90'. "En el año 1991 se implementa la reforma a la Ley Orgánica Constitucional de Municipalidades la cual establece, por primera vez en la historia constitucional de Chile, que la Municipalidad es una Corporación de Derecho Público dotado de autonomía administrativa, con personalidad jurídica y patrimonio propio. Asimismo, se señala que su objetivo es promover el desarrollo económico, social y cultural de la comuna o agrupación de comunas" (Benítez 1998:63).

Este sentido de autonomía tenía el objetivo central de promover la participación política para rearticular la incidencia y la toma de decisiones por parte de la ciudadanía, gestionando los municipios como organismos autónomos al servicio de la comunidad, lo que pareciera que se ha quedado sólo en el ejercicio electoral al momento de decidir por las autoridades comunales, sin trascender en una inclusión permanente de la comunidad en el proceso de desarrollo comunal. "El tema de la participación ciudadana si bien es anunciada y enunciada no constituye un tema relevante en la agenda de la Asociación Chilena de Municipalidades. De hecho las cuatro temáticas que conforman el armazón del discurso son Autonomía, Competencias, Financiamiento y Estructura. Así, entonces, queda la sensación que la participación se remitiera solamente a la posibilidad que tienen los ciudadanos de elegir a sus alcaldes y concejales cada cierto periodo de tiempo" (Benítez 1998:67); lo que se traduciría en un cuestionamiento a la gestión municipal por estar sustentada en el paradigma racionalista administrativo de la administración pública. Se genera una suerte de acción y de intervención permanente sobre el espacio local lo que hace que las autoridades pierdan la visibilidad sobre las diferencias sociales, y a la vez que tienda a anular la participación, la que les llevaría a perder el control sobre la acción: "Las instituciones trabajan un concepto estrecho de descentralización y reconocimiento de las diferencias incapaz de producir flujos de visibilidad social, salvo aquella operada por los administradores y concentrada en eventos de sometimiento comunitario, es decir proyectos-constructos que adelgazan al ciudadano y lo envuelven en la lógica de la dependencia institucional" (Ossa 1998:152), generando redes que reproducen, mediante estrategias comunicacionales, el individualismo asistido de la comuna, a través de un solo actor, el alcalde, que define los espacios de legitimación de la institución municipal.

Esta forma de legitimar el espacio comunicacional aminora la forma de diálogo como instancia de participación dentro de la comuna, y reproduce la transmisión del poder mediante un solo actor institucional, que confirma la visión instrumental de las comunicaciones, "que determina el lugar que los actores sociales adquieren en los circuitos institucionales y los grados de inserción tolerados, de acuerdo a una lectura de poder que utilizan las comunicaciones como dispositivo funcional de mensajes y recepciones. La cotidianeidad y la subjetividad son excluidas del trabajo y el valor informativo se perfila como única manera de entenderse con la comunidad. El valor informativo no distingue y universaliza, excluye en su generalidad y al hablar de "todos" ilusiona su propia práctica como democracia y 
encuentro" (Ossa 1998:154); lo que a hecho desaparecer el carácter de proceso en las comunicaciones como posibilidad de inserción social, de solución de problemas sociales, y como inclusión de la diferencia; resaltando a los canales de comunicación como meros transmisores de información.

Dentro de esta realidad no hace falta recalcar que el individualismo contemporáneo ha afectado en los patrones clásicos de organización comunitaria que se podía observar al interior de las villas, de las poblaciones o de los barrios; y frente a este cambio e impacto es necesario que la Comuna reoriente su gestión revitalizando el grado de injerencia de las comunidad, de la sociedad civil, y en particular, de los jóvenes secundarios. La Municipalidad se articula en la actualidad a partir de la siguiente matriz: Disciplina, Jerarquía autoritaria, Delegación de responsabilidades, Individualismo asistido, y el Debilitamiento del grupo, como forma de satisfacción de necesidades; lo que no esta dando cabida a una participación no competitiva que revitalice a la comunidad. "El predominio comunitario se traduce en que los miembros de las organizaciones se asocian de manera no competitiva ni pactada, ni ordenados por pautas rigurosas de institucionalización" (Soto 1998:121); para lo cual sería conveniente articular una nueva matriz sustentada en principio como: La Sobrevivencia Colectiva, la Solidaridad, la Seguridad, y el Autoestima., una nueva matriz que intente rearticular el sentido comunitario de la sociedad.

Y que a la vez se impulse en relación a un sentido de participación adecuado a modalidades vigentes en los jóvenes, en formas concretas e inmediatas, rápidas y eficaces de participación. "Tienen mayor espacio las formas que dan paso a una participación en pos de lo visible, lo palpable y entendible a nivel de la vida cotidiana de la población y del barrio" (Soto 1998:134). Que den espacios a nuevos conceptos de participación y de articulación con líderes y grupos momentáneos, ligados a formas concretas de identificación y de solución de problemas; como por ejemplo: Lo desechable, que corresponden a grupos que se constituyen en relación a un objetivo determinado, y que una vez alcanzada la meta se diluyen como tales; "la ventaja de estas formas de asociación, es que logran convocar a muchos participantes, alcanzando un éxito palpable. Lo chatarra, que corresponde a grupos de participación funcionales y utilitarios ligados a objetivos específicos de articulación, que logran influir en el medio por su sola presencia mediante el temor y la amenaza; podrían ser "grupos informales ligados al consumo de drogas, delincuencia, e incluso sectores de las barras bravas". De envoltorio, son grupos de escasos participantes, pero donde el liderazgo queda más marcado al momento de alcanzar una meta; "poseen cierto grado de iniciativa personal y cupular, lo que les permite ligarse a diferentes instancias públicas y privadas, para realizar actividades y eventos efímeros" (Soto 1998:126).

Son grupos que podemos localizar en la comuna de La Florida, y que son parte del individualismo, y de su frase tan típica: no estar ni ahí, que en muchos casos los condena por las autoridades que son expertas en reprimir lo que no comprender, y de aplicar la tolerancia como una pseudo convivencia social al interior de la comunidad. Son grupos que no tienen sede, ni un espacio definido de gestión o de organización, y que transitan por la inmediatez temporal y espacial del territorio; y que a la vez son dominados por el mercado, el cuál los identifica claramente con sus formas consumistas de convivencia: "La participación en el mercado no sólo es un consumo de productos materiales ni de servicios, también se ha transformado en una necesidad psicológica de estar presente, de estar integrado a la sociedad, a través del consumo de productos, moda; radios, televisores en color, videos, videocasetes son formas de integración" (Soto 1998:135). Algo que para los jóvenes observados de la Florida es algo tan típico, con lo cual se sienten plenamente identificados como núcleo central de la comuna, el catorce; un lugar que reúne todas las estrategias del mercado impulsando el consumo máximo como forma de integración, y a la vez observado por la Municipalidad, que se emplaza en el mismo sector.

\section{Conclusión}


Frente a este contexto puntual de aplicación cabe preguntarse, teniendo en cuenta las descripciones que hace Touraine al momento de definir al sujeto como el principal pilar de la democracia, ¿Cuál es la calidad del sujeto en Latino América?, realmente contamos con sujetos capaces de generar un cambio a nivel político, sujetos que argumenten sólidamente acerca de su identidad, sabemos que con algunas comunidades indígenas se puede contar, y también con algunas suertes de regionalismo, como es el caso de Chiapas, pero en relación a la gran masa de las ciudades que constituye el gran porcentaje de los electores, al habitante urbano que se desenvuelve diariamente en ambientes cosmopolitas, es en ellos en donde hay que centrar la respuesta de la interrogante. Para algunos autores tenemos "un sujeto a merced de las modas publicitarias que se encubran de autorrealización y experiencia del yo. Un sujeto débil de este talante es una presa fácil para la aceptación de los mitos del momento, sobre todo, si se presenta con ropaje exótico [...] En que prima el individuo sin sujeto... predomina el olvido de los otros y del sufrimiento de los vencidos de la historia. Un pensamiento de este género, más que un sujeto débil, nos oferta un sujeto fatigado y decrépito" (Mardones 1990:27).

Los sujetos latinoamericanos están inmersos en las modas de la posmodernidad, lo que los ciega frente a su propia identidad como sí mismos, y a identificarse con un grupo en una suerte de pertenencia. Touraine lo plantea de la siguiente manera: "El pasaje del individuo consumidor al individuo sujeto no se opera mediante la simple reflexión o por la difusión de ideas. Sólo se opera por la democracia, por el debate institucional abierto por el espacio dado a la palabra, en particular a la de los grupos más desfavorecidos [...] La democracia se sienta sobre la responsabilidad de los ciudadanos de un país. Si estos no se sienten responsables de su gobierno, porque éste ejerce su poder en un conjunto territorial que les parece artificial o ajeno, no puede haber ni representatividad de los dirigentes ni libre elección de éstos por los dirigido [...] cada uno se define enteramente por su pertenencia a una comunidad." (Touraine 1995:219-220).

Es el sujeto el que forja su identidad a través de tradiciones, de socialización, de la comunicación, de la razón comunicativa que genera la acción comunicativa, como diría Habermas, para la constitución de "un debate institucional abierto". Las ideas de Touraine y de Habermas se unen en el concepto de sujeto comunicativo, lo que daría asiento a una democracia participativa, sustentada en la autodeterminación, la pertenencia, la autorrealización, y el reconocimiento por lo ajeno, por lo alterno, por el otro, en conjunto con la Sobrevivencia Colectiva, la Solidaridad, la Seguridad, y el Autoestima., dando origen a una nueva matriz que intente rearticular el sentido comunitario de la sociedad, el sentido de pertenencia y de territorialización en lucha con el individualismo asistido que rompe y fragmenta el sentido de identidad y participación, dentro de un marco crítico orientado hacia la posmodernidad, por su esencia de ser menos unitaria que la moderna, reflejando una aceptación desprejuiciada por lo plural, donde predomina el olvido de los otros y el perfil de un sujeto fatigado y decrépito.

Una reflexión que nos hace volver a la interrogante inicial: ¿Podemos vivir juntos?, un cuestionamiento cuya respuesta apunta a una necesaria integración de las identidades por profundizar en las relaciones intersubjetivas donde la posición estratégica del sujeto resalta por sobre la del individualismo asistido, donde la comunicación participativa en cuanto a democracias participativas o deliberativas, en la línea habermasiana, es fundamental en el reconocimiento del uno por el otro. Sólo de esta manera se podrá establecer una integración económica, social, cultural, desde una visión optimista de la modernidad como proyecto inacabado.

Un proyecto inacabado que se puede dinamizar a través de un cuestionamiento crítico hacia las municipalidad, como espacio social y político, y a su eje articulador en base a la matriz de: Disciplina, Jerarquía autoritaria, Delegación de responsabilidades, Individualismo asistido, y el Debilitamiento del grupo, como forma de satisfacción de necesidades; lo que no esta dando cabida a una participación no 
competitiva que revitalice a la comunidad, conformando una participación remitida solamente a la posibilidad que tienen los ciudadanos de elegir a sus representantes.

Es necesario generar un espacio crítico que de cabida a una inclusión de la cotidianeidad y de la intersubjetividad como prácticas sociales atingente en la revitalización del sujeto como agente de cambio contra las redes que reproducen, mediante estrategias comunicacionales, el individualismo asistido de la comuna, a través de un solo actor, el alcalde, que define los espacios de legitimación de la institución municipal.

Realidad que se evidencia al constatar representaciones sociales excluyentes y asistidas, ya que los jóvenes observados de la Florida se sienten plenamente identificados con el núcleo central de la comuna, el catorce; un lugar que reúne todas las estrategias del mercado impulsando el consumo máximo como forma de integración, y a la vez observado por la Municipalidad, que se emplaza en el mismo sector, pero a la vez de fragmentación y transgresión identitaria.

\section{Bibliografía}

Arriarán, Samuel. 1997. Filosofía de la Posmodernidad. México: Facultad de Filosofía y Letras UNAM.

Benítez, J. 1998. "La Asociación Chilena de Municipalidades ¿Un nuevo discurso en el municipio?”. En: Salazar, G. y J. Benítez. Autonomía, espacio y gestión. El municipio Cercenado. Santiago: Ed. Lom.

Bourdieu, Pierre. 1997. Razones prácticas. Sobre la teoría de la acción. Barcelona: Ed. Anagrama.

CEPAL. 1997. Aspectos Sociales de la integración. Serie Políticas Sociales. Nº 14 vol. II.

Censes. 1990. Cuadernos Censes. № 13-14.

Habermas, J. 1986. La Reconstrucción del Materialismo Histórico. Madrid: Ed. Taurus.

Habermas, J. 1987. Teoría de la Acción Comunicativa Vol. I. Madrid: Ed. Taurus.

Habermas, J. 1989. El discurso filosófico de la modernidad. Madrid: Ed. Taurus.

Jodelet, D. 1986. "La Representación Social: Fenómenos, Concepto y Teoría". En: Moscovici, S. Psicología Social II. Pensamiento y Vida Social, Psicología Social y Problemas Sociales. Barcelona: Editorial Paidós.

Mardones, José María. 1990. "El Neoconservadurismo de los Posmodernos”. En: Vattimo, G y otros autores. En torno a la Posmodernidad. Barcelona: Ed. Antrophos.

Ossa, Carlos. 1998. "Ciudad: Abolición y Desconcierto”. En: Salazar, G. y J. Benítez. Autonomía, espacio y gestión. El municipio Cercenado. Santiago: Ed. Lom.

Ramírez, Juan Andrés. 1990. "Catecismo Breve de la Posmodernidad”. En: Vattimo, G y otros autores. En torno a la Posmodernidad. Barcelona: Ed. Antrophos. 
Soto Vargas, C. 1998. "Formas contemporáneas de participación. Elementos para un perfil de neoparticipantes". En: Salazar, G. y J. Benítez. Autonomía, espacio y gestión. El municipio Cercenado. Santiago: Ed. Lom.

Touraine, A. 1995. ¿Que es la Democracia? Buenos Aires: Ed. Fondo de Cultura Económica.

Vattimo, G. y otros autores. 1990. En Torno a la Posmodernidad. Barcelona: Ed. Antrophos. 